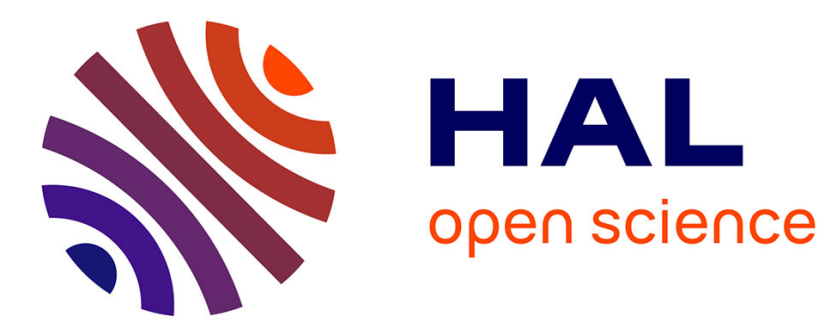

\title{
Human factors integration in manufacturing systems design using function-behavior-structure framework and behaviour simulations
}

\author{
Jean-Yves Dantan, Ismail El Mouayni, Leyla Sadeghi, Ali Siadat, Alain \\ Etienne
}

\section{To cite this version:}

Jean-Yves Dantan, Ismail El Mouayni, Leyla Sadeghi, Ali Siadat, Alain Etienne. Human factors integration in manufacturing systems design using function-behavior-structure framework and behaviour simulations. CIRP Annals - Manufacturing Technology, 2019, 68 (1), pp.125-128. 10.1016/j.cirp.2019.04.040 . hal-03488212

\section{HAL Id: hal-03488212 \\ https://hal.science/hal-03488212}

Submitted on 20 Dec 2021

HAL is a multi-disciplinary open access archive for the deposit and dissemination of scientific research documents, whether they are published or not. The documents may come from teaching and research institutions in France or abroad, or from public or private research centers.
L'archive ouverte pluridisciplinaire $\mathbf{H A L}$, est destinée au dépôt et à la diffusion de documents scientifiques de niveau recherche, publiés ou non, émanant des établissements d'enseignement et de recherche français ou étrangers, des laboratoires publics ou privés.

\section{다)(1) $(5$}

Distributed under a Creative Commons Attribution - NonCommerciall 4.0 International 


\title{
Human factors integration in Manufacturing Systems Design using Function- Behaviour-Structure framework and behaviour simulations
}

\author{
Jean-Yves Dantan (2) a, Ismail El Mouayni b, Leyla Sadeghi c, Ali Siadat a, Alain Etienne a \\ ${ }^{a}$ LCFC, Arts et Métiers-ParisTech-Metz, HESAM, Université de Lorraine, 4 rue Augustin Fresnel, 57078 Metz Cedex 3, France \\ ${ }^{b}$ Université de Lorraine, CRAN, F-88000 Epinal, France \\ c Industrial Engineering Department, Sharif University of Technology, Azadi Avenue, Tehran 11365-11155, Iran
}

Human factors integration is often achieved during detailed manufacturing system design phases. Whereas, significant decisions are token when overall primary design is set. Accordingly, this paper introduces a new design framework based on the Function-Behaviour-Structure to consider human factors earlier in the design process. The main idea consists in analysing the behavioural interactions between workers and manufacturing equipment driven from the system structure. Relevant human and health related factors to these interactions are then integrated in the analysis. These interactions are model and simulated to assess the system design using specific productivity and working conditions indicators.

Manufacturing System, Design Method, Human Aspect

\section{Introduction}

Considering human factors has always been an issue in the analysis and the optimization of manufacturing system, especially during its design process [1]. In such systems, the people who carry out tasks and activities manually seem to be a key element of the system's performance [2]. Admittedly, human operators can provide the needed flexibility in the system and thus improve productivity. In the opposition, in some cases, these operators are typically seen as a source of unpredictability causing errors and hazardous situations [3].

As a result, focusing mainly on technical aspects leads to manufacturing systems with an overestimated production capacity [4]. Regarding the worker's health and safety, the review of interventions made for enhancing these aspects seems to be non-conclusive [5]. Therefore, more attention should be given to human factors to ensure productivity, health and safety requirements.

As a matter of fact, several approaches and tools were proposed to consider human factors during manufacturing system design process. Tools such as Human Digital Models, Predetermined Motion Time Systems [6] and Discreet Event Simulation software [7] can be used to predict respectively the biomechanical hazards, standard times and workload and how human factors (such as learning and fatigue) impact the task processing time and error probabilities [8].

Regarding the whole manufacturing design process, there is three main approaches for achieving human factors integration using these tools [9] :

- Classical approaches which use the available knowledge in shape of models that can be incorporated in form of criteria to predict working conditions and validate the tasks requirement regarding ergonomics, health and safety of human operators;

- Socio-technical approach which considers that a manufacturing system is composed of two sub-systems that must be jointly optimized: the sub-technical system, referring to the manufacturing equipment (machines, workstations...) and the social sub-system (workers within a specific organization);

- Human centred-approach which aims at establishing an anthropocentric manufacturing system by driving the design objectives toward reinforcing the human position in the system (enhancing workers collaboration, knowledge...). This approach leads to systems that tend to enrich task and parallelize the physical flow.

Nevertheless, these approaches only give guidelines for the manufacturing system design. Yet, except few works [3] [10] [11], few tooled frameworks have been proposed. Indeed, there still exists a gap between what is imagined for a manufacturing system during its design and what is happening during its operating phase. A substantial part of this uncertainty is due to human-related aspects in the system. The researchers had attempt to consider human being in the design process of manufacturing systems at different levels: frameworks, tools and models. For example, Slatter and Husband [3] developed an alternative human-centred approach for Man-Machine systems design, in which technical and human aspects of manufacturing systems are considered parallel from the earliest design process. Shahrokhi and Bernard [12] proposed a multi agent/ multi-scale human modelling approach to facilitate the modelling and analysis of human performance in computerized 3D platforms. Recently, Sadeghi et al. [10] proposed a design framework based on interaction of Function-Behaviour-Structure (FBS) [13] and Product-Service System, which allows considering product behaviours and its interaction with service activities. This work can be extended to manufacturing systems by considering two distinguished behaviours: the expected behaviours of the manufacturing equipment and the behaviours of human resources. The proposed FBS framework allows the analysis of the interactions between human behaviour (activity) and production system behaviour (production task and energy flow) 
which is helpful for working situation analysis and the hazardous conditions [14].

To improve the productivity of the production system with the integration of human factors, a new deployment of the FBS framework is proposed in this paper. In fact, the analysis of the interactions between the human Behaviour (fatigue, learning ...) and the production system Behaviour (productivity, quality) allows to quantify the impact of a design decision on the production system performance and the human factors. The section 2 presents the FBS framework. The section 3 presents the human factors integration using simulation tools. The section 4 presents the impact of a design decision on the key performance indicators and the human factors. The last section states the main conclusions of this work.

\section{Proposed design framework}

The aim of this section is to propose a manufacturing system design framework which integrates human factors. To consider worker's safety and health, as a relevant human factor to manufacturing system design, [10] proposed to extend FBS framework by integrating human behaviour in design process. This integration aims to validate design configuration by analysing work situation. This extension highlights the need of considering human performance in the design process, which allows work situation analysis. Originally, FBS modelling covers the aspect of behaviour and helps to model design as a process and to capture the nature of the concepts manipulated during it by using a knowledge representation diagram [15]. Function in FBS is defined as being the intermediary between the goal and the behaviour of a system [13]. The FBS model focuses more on the design process which is considered to be a transformation from intentions to structure. Early system design is considered as a process of mapping functions, behaviours and structure. Further details regarding FBS are given in [13] [15].

The proposed design framework in this paper is an adaptation of the FBS design theory. A clear distinction of the manufacturing equipment's behaviours, from the human resources is made. During the preliminary design phase, this distinction allows to model and simulate the behaviours interactions and therefore, to analyse the working conditions, the system performance, and consequently to find potential hazards.

It should be noted that the basis of this proposition is Gero's FBS ontology applied to the requirements definition of systems. Function is defined as what the system should be able to achieve expressed in terms of purpose, what it is for [16]. Behaviour is defined as the manner by which the system is expected to perform its functions and when. It describes how the system and its components work [16]. Functions could be realized through behaviours. A behaviour can be either an activity or a property. Behaviours are assigned to a structure element which can be human or manufacturing equipment, or space.

The proposed design framework is illustrated in Figure 1. In this figure 'Sys' refers to all resources, 'Me' refers to manufacturing equipment and ' $\mathrm{Hr}$ ' refers to Human resources. The proposed design framework is decomposed into following steps:

1. Goal definition to drive the decisions along the framework. Goals of the System (Gsys) are the inputs of the design process; they are defined and refined with the stakeholder.

2. Function generation expresses what the system should do to attain goals. When a goal cannot be further refined, a function ( $F_{\text {Sys }}$ ) must be formulated.

3 and 4. Function allocation to define how functions will be implemented in terms of behaviours associated to main structure elements.
5. Behavioural refinement to describe the internal functioning (5.1) of the $S_{\text {Sys }}$ necessary to fulfil the $F_{\text {Sys }}$ allowing the achievement of the Gsys in terms of its components' behaviour $\left(\mathrm{B}_{\mathrm{Hr}}\right.$ and $\mathrm{B}_{\mathrm{Me}}$ ). These behaviours refer to processes and activities to be performed (5.2) by a set of resources ( $\mathrm{S}_{\mathrm{Me}}$ and $\mathrm{S}_{\mathrm{Hr}}$ ).

6 . Processing to reduce the number of requirements. This step is decomposed into three steps. In Step 6.1 an operational metaspace gathering all the necessary conditions is assigned to each operation. This operational meta-space is considered as part of the manufacturing equipment's behaviour $\left(\mathrm{B}_{\mathrm{Me}}\right)$. As a result, there are as many operational meta-spaces as operations to perform. Step 6.2 helps the operational meta-spaces be linked to each other. Step 6.3 allows to reduce amount of operational metaspaces through their grouping based on their conditions.

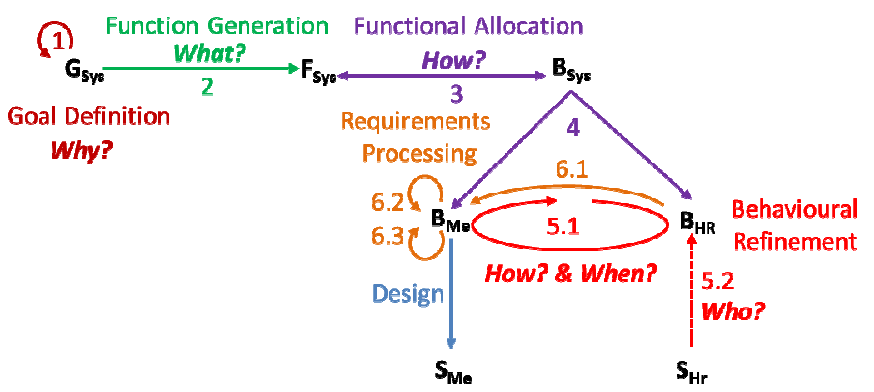

Figure 1. Human factors integration in FBS framework

Step 1 to step 3 (from definition of goal to function generation) cover strategic level of design framework and step 6 (processing) covers operational level of framework (Figure 1). Following sections explain simulation incorporation into FBS framework which allows behaviour analysis.

\section{Behaviour simulation within FBS framework}

According to [17], simulation is an appropriate tool to consider performance of manufacturing systems at earliest design stages. It is a commonly used technique for manufacturing system design and operations management. It helps designers to overcome the system complexity and doesn't require explicit mathematical model to predict the system behaviour [18] as simulation modelling is achieved through system imitation and not through system behaviour explicit description. In this section, we want to explore how simulation can be used following an FBS framework.

Simulation conceptual modelling is one of the most critical aspects of a simulation project. It represents a partial view of the system that can be used to assess its behaviour using one the simulation mechanisms. Using simulation within FBS means that the simulation model should be compatible with the seven knowledge representations on which FBS is articulated (see Figure 1). Accordingly, the metamodel shown in Figure 2 introduce main concepts manipulated during a simulation project.

Based on this metamodel, simulation-based design methodology according to FBS framework consists on the following steps:

1. Designing activities ensuring the system functions by defining operations subsets;

2. Selecting entities for activities processing;

3. Modelling behaviour elements corresponding to each couple (activity, structure's entity)

4. Identifying attributes which characterizes each behaviour element;

5. Introducing measures needed for key performance indicators calculation.

6. Assessing design using key performance indicators 
7. Go to 3 if chosen entities do not fulfil functional requirements;

8. Redesigning activities if a feasible solution cannot be found.

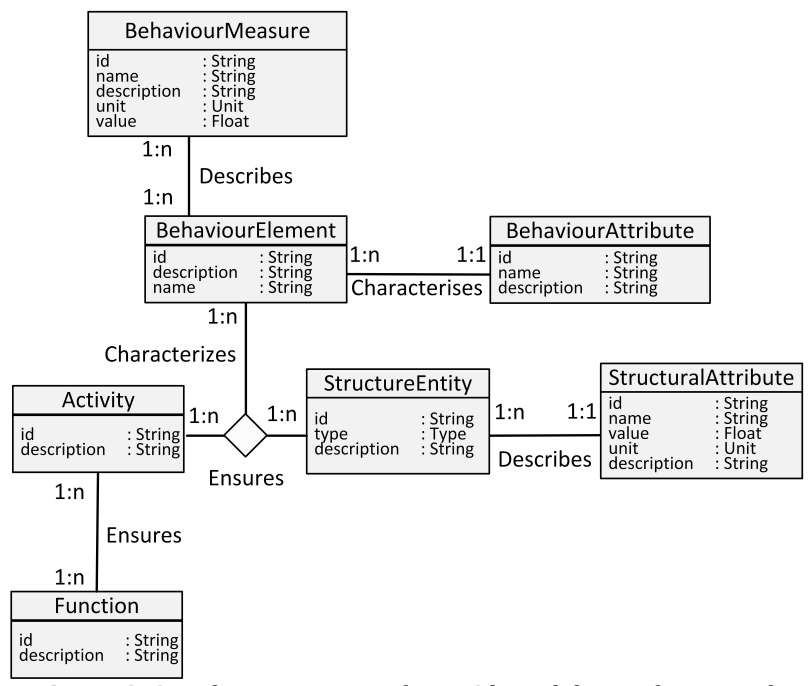

Figure 2. Simulation concepts for FBS based design framework

To model activities, most simulation tool uses steps incorporated in a process. In FBS framework, each activity is characterised through a set of behaviour elements formalized using the following equation:

$$
\boldsymbol{b}_{\boldsymbol{m}}=f\left(\boldsymbol{b}_{\boldsymbol{a}}\right)
$$

Where $\boldsymbol{b}_{\boldsymbol{m}}$ is a vector of behaviour measures and $\boldsymbol{b}_{\boldsymbol{a}}$ is the behaviour attributes vector. For example, a behaviour of a machining activity such as milling can be measured by its processing time and the surface quality obtained. This behaviour is a function of the cutting speed and the spindle rotation speed. These parameters represent the behaviour attributes for this activity.

\section{Assembly line design with consideration of worker factors}

This section tackles a case study to illustrate the proposed methodology.

\subsection{Case study introduction}

This section addresses a blinder assembly line case study. 14 operations are required to assemble one product. Their precedence graph and average processing time Top (min) are given in Figure 3. These processing times are assumed to follow a normal distribution with a standard deviation equal to Top/12 for automatic operations, and Top/6 for manual operation. Operation 1, 3, 5, 10 are automatic and the processing times indicated in Figure 3 are after automation. For remainder, precedence graphs describe precedence constraints between operation. A node represents an operation. An arrow between two nodes represent a precedence constraint.

The cycle time required with consideration of system reliability ( $90 \%$ based on the analogy with an existing assembly line) is $0.55 \mathrm{~min}$. In such rate, linear configuration is more appropriate. Accordingly, Kilbridge \& Wester method [19] for line balancing is used for operations subsets construction. This method uses Longest Processing Time and the lowest number of successors as priority rules for operation allocation. When the cycle time is reached a new workstation is opened. Therefore, each subset corresponds to a workstation denoted $W_{i}$, each with a set of behaviour elements. The objective is to investigate the effect of these behaviours on the overall system performance.

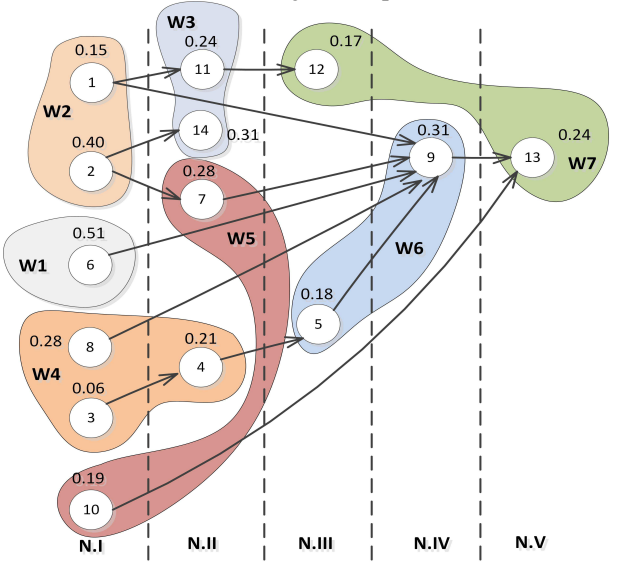

Figure 3. Precedence graph with operations' subsets

\subsection{Modelling behaviour elements}

To consider human behaviour in the simulation, the following assumptions are made:

- Workers are considered experimented. Therefore, learning effect is neglected;

- One worker is assigned to one workstation.

The main worker's activity consists on processing tasks allocated to his workstation. Processing these operations will induce fatigue rise with a specific rate depending on the nature of operation processed (automatic or manual). Automatic operation implies lower fatigue rate as worker should at least supervise the operation. The fatigue is modelled using (2):

$$
F_{t+\Delta T}=w \cdot\left\{1-\left(1-F_{t}\right) \cdot e^{-\lambda \cdot \Delta T}\right\}+(1-w) \cdot F_{t} \cdot e^{-\mu \cdot \Delta T}
$$

Where $F_{t}$ is the fatigue index at t. $F_{t}$ being equal to 1 means that the worker is fatigued. The parameter $w$ is the worker state between $t$ and $t+\Delta T$. It is equal to 1 if worker is busy, equals to 0 if Idle. The parameter $\lambda$ is the fatigue rate. Its value is estimated by analysing stress factors such as poster, weight or eye strain [20]. The parameter $\mu$ is the recovery rate. It is estimated by mapping the second part of (2) with the proportion of time needed for recovery calculated based on stress factors and using time allowances tables [20]. The method for calculating $\lambda$ and $\mu$ is detailed in [21].

The second relevant behaviour is the human proactivity regarding fatigue. If the worker has time allowances, he will take a break to recover from fatigue. This is possible if the workstation input buffer is not totally full. This can be expressed by (3)

$$
A=1-E\left[\frac{I_{t}}{I_{c}}\right]
$$

Where $E$ is the integer part function, $I_{t}$ is the size of the input buffer at the instant $t$ and $I_{c}$ is its capacity (equal to 3 for all workstations). $A$ being equal to 1 means that worker can take a break, besides planned ones (break of $15 \mathrm{~min}$ at $10 \mathrm{~h}$ and $16 \mathrm{~h}$, a break of $1 \mathrm{~h}$ at $12 \mathrm{~h}$ ). The fatigue impacts the worker's reliability as modelled in (4):

$$
P_{H E}=c . F_{t}^{\alpha}
$$

where $P_{H E}$ is the human error probability. The parameters $c$ (0.5) and $\alpha$ (2.5) are used to map the model with reliability empirical data. Likewise, a semi-automatic workstation can break after a time between failures $T_{b f}$ following an exponential distribution with a mean time between failure equal to $60 \mathrm{~min}$. Finally, part arrivals follow a normal distribution with a mean equal to $0.66 \mathrm{~min}$ and standard deviation equal to $0.034 \mathrm{~min}$. 


\subsection{Design assessment}

The simulation conducted under simulation software SIMIO gives an estimation of the system throughputs including rejected parts due to human errors: 601 assembled blinders, including 41 rejected. A further examination of fatigue distribution shows that worker 2 and 3 have a fatigue index relatively high in comparison with the rest of workers, leading to a rise in human error probability and altering working conditions.

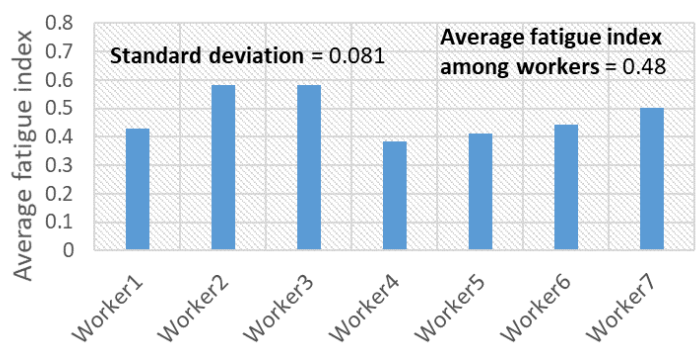

Figure 4. Workers average fatigue index in initial configuration

\subsection{Redesigning activities.}

The case study introduced in the previous section showed that balancing the system based on capacities is inefficient. Focus should rather be given to flow with consideration of variations by including behaviours in the analysis. To reduce workstation 2 and 3 workload, reallocation of operations between stations $2,3,5$ and 7 is made. W7 performs operation 14 and 13, W3 get operations 1, 12 and 10, W5 performs 7 and 11. Finally W2 kept only operation 2 .

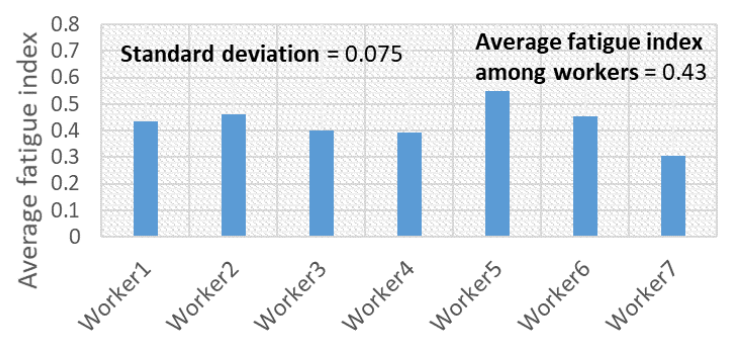

Figure 5. Workers average fatigue index in enhanced configuration

The simulation of the new configuration shows an improvement in throughputs (32 rejected, 603 in total). The Figure 5 shows better workload among workstations indicated by lower standard deviation (better balancing) and average fatigue index among workers

\section{Conclusions}

There are numerous researches addressing human factors integration in the manufacturing system design process. Yet, integration of these factors in early operational design and analysis still a challenge [1], leading to design uncertainty, hazards and system productivity overestimation [4].

Accordingly, we proposed an adaptation of the design FunctionBehaviour-Structure theory which distinguishes the expected behaviours of the manufacturing equipment from the human resources behaviours. This distinction allows to model and to simulate the behaviours interactions during the preliminary design phase, therefore, to jointly analyse productivity and working conditions.

This distinction between the behaviour of manufacturing equipment and human operators' behaviour pushes the designer toward analysing the interactions between them. To address these interactions simulation can be used within the proposed framework. Modelling and simulating equipment and human behaviours gives the designer better insight on how fatigue and other factors can impact work situation (workload, stress ...). These factors may magnify or reduce the probability of error that can be linked to productivity decrease and even accidents in workplaces, as illustrated through the case study.

\section{Acknowledgement}

The authors gratefully acknowledge the support of the common laboratory LC2S between LCFC and INRS; and the Industrial Research chair "SYSTEMES DE PRODUCTION RECONFIGURABLES, SURS ET PERFORMANTS" of Arts et Métiers, co-founded by Thyssenkrupp Presta France, UIMM Lorraine (fond F2i) and the European Regional Development Fund ("Programme opérationnel FEDER-FSE Lorraine et Massif de Vosges 20142020").

\section{References}

[1] Jensen, P.L., Alting, L., 2006, Human Factors in the Management of Production, Annals of the CIRP, 55/1:457-460.

[2] Noweir, M. H., 1984, Noise exposure as related to productivity, disciplinary actions, absenteeism, and accidents among textile workers, J. Safety Res. 15:163-174.

[3] Slatter, R.-R., Husband, T.M., Besant, C.B., Ristic, M.R., 1989, A Human-Centred Approach to the Design of Advanced Manufacturing Systems, Annals of the CIRP, 38/1:461-464.

[4] Baines, T., Mason, S., Siebers, P.-O., Ladbrook, J., 2004. Humans: the missing link in manufacturing simulation? Simul. Model. Pract. Theory 12:515-526.

[5] Tuncel, S., Genaidy, A., Shell, R., Salem, S., Karwowski, W., Darwish, M., Noel, F., Singh, D., 2008. Research to practice: Effectiveness of controlled workplace interventions to reduce musculoskeletal disorders in the manufacturing environment-critical appraisal and meta-analysis. Hum. Factors Ergon. Manuf. Serv. Ind. 18:93-124.

[6] Genaidy, A.M., Mital, A., Obeidat, M., 1989. The validity of predetermined motion time systems in setting production standards for industrial tasks. Int. J. Ind. Ergon. 3:249-263.

[7] Pidd, M., 2004. Computer Simulation in Management Science, 5 edition. ed. Wiley, Chichester, England ; Hoboken, NJ.

[8] El Mouayni, I., Etienne, A., Siadat, A., Dantan, J-Y., Lux, A., 2017, AEN-PRO: Agent-based simulation tool for performance and working conditions assessment in production systems using workers' margins of manoeuver, IFAC, 50/1:14236-14241

[9] Jensen, P.L., 2002. Human factors and ergonomics in the planning of production. Int. J. Ind. Ergon. 29, 121-131.

[10] Sadeghi, L., Dantan, J.Y., Mathieu, L., Siadat, A., Aghelinejad, M., 2017, A design approach for safety based on Product-Service Systems and FunctionBehavior-Structure, CIRP Journal of Manufacturing Science and Technology, 19:44-56.

[11] Sadeghi L., Dantan J.-Y., Siadat A., Marsot J., 2016, Design for human safety in manufacturing systems: applications of design theories, methodologies, tools and techniques, Journal of Engineering Design, 27/12:844-877.

[12] Shahrokhi, M., Bernard, A., 2009, A framework to develop an analysis agent for evaluating human performance in manufacturing systems, CIRP Journal of Manufacturing Science and Technology, 2/1:55-60.

[13] Gero, J. S., Kannengiesser, U., 2004, The Situated Function-Behaviour-Structure Framework, Design Studies 25:373-391.

[14] Sadeghi, L., Mathieu, L., Tricot, N., Al Bassit, l., 2015, Developing a Safety Indicator to Measure the Safety Level During Design for Safety. Safety Science, 80:252-263.

[15] Gero, J. S. 1990, Design Prototypes: A Knowledge Representation Scheme for Design, AI Magazine 11/4:26-36.

[16] Kannengiesser, U., Gero, J.S., 2011, A Framework for Constructive Design Rationale. Design Computing and Cognition '10, 135-153.

[17] Neto, A., Ramalho, P., Vila, E., Filho, G., 2010. A simulation-based evolutionary multiobjective approach to manufacturing cell formation. Comput. Ind. Eng. $59,64-74$.

[18] Negahban, A., Smith, J.S., 2014. Simulation for manufacturing system design and operation: Literature review and analysis. J. Manuf. Syst. 33, 241-261.

[19] Kilbridge, M. D. Wester, L. A Review of Analytical Systems of Line Balancing, Oper. Res., vol. 10, no. 5, pp. 626-638, Oct. 1962.

[20] Kanawaty, G., International Labour Office, 1992. Introduction to work study. International Labour Office, Geneva.

[21] El Mouayni, I., Etienne, A., Lux, A., Siadat, A., Dantan, J.-Y., 2019. A simulationbased approach for time allowances assessment during production system design with consideration of worker's fatigue, learning and reliability. Comput. Ind. Eng. https://doi.org/10.1016/j.cie.2019.01.024 